\title{
Merkel Cell Carcinoma - A Rare Form of Skin Cancer with New Therapeutic Options
}

\author{
DANA LUCIA STANCULEANU ${ }^{1,2}$, OANA TOMA2, CRISTIAN VASILE², CORNELIA NITIPIR ${ }^{1,3}$, ALINA BODILCU², RALUCA MIHAILA ${ }^{2}$, \\ RAZVAN HAINAROSIE ${ }^{3}$, CRISTIAN DRAGOS STEFANESCU³, DANIELA ZOB* \\ ${ }^{1}$ Carol Davila University of Medicine and Pharmacy, Department of Oncology, 8 Eroii Sanitari Str., 050474, Bucharest, Romania \\ ${ }^{2}$ Prof. Dr. Alexandru Trestioreanu Institute of Oncology, Department of Medical Oncology I, 252 Fundeni Str., 022328, Bucharest, \\ Romania \\ ${ }^{3}$ Carol Davila University of Medicine and Pharmacy, 8 Eroii Sanitari Str., 050474,Bucharest, Romania
}

Merkel cell carcinoma (MCC) is a rare primaryneuroendocrine carcinoma of the skin, with very aggressive behavior. Etiological factors contributing to MCC development, include exposure to UV radiation, infection with Merkel cell polyomavirus (MCPyV) and chronic immunosuppression. It is commonly found in regions of the body that are exposed to sun $-55 \%$ of cases are located in the head and neck. The 5 years survival rate for metastatic disease is approximately $25 \%$. The estimated mortality rate for MCC is between $33 \%$ and $46 \%$. Therapeutic options for MCC depends on disease characteristics (stage of disease at presentation, location of the tumor, regional lymph node involvement, comorbidities and performance status of the patient) and it includes multimodal treatments like surgery, chemotherapy and emerging immunotherapeutic treatments with early promising results. Our clinic experience is very limited with this type of malignancy, only three cases were diagnosed and treated in our department, but with encouraging results regarding the newest immunotherapeutic options, with good quality of life and results similar with the data from the literature.

Keywords: Merkel cell carcinoma, cutaneous neuroendocrine carcinoma, immunohistochemistry, multimodal treatment, immunotherapy.

Merkel cell carcinoma (MCC) is a rare primary neuroendocrine carcinoma of the skin, with very aggressive behavior, and it is also called trabecular carcinoma (or trabecular cancer). It has the highest mortality rate among all malignancies and especially between skin malignancies [1,2]. These neuroendocrine cells that were first discovered by Merkel in 1875 and its origin was difficult to establish, due to the fact that the cell exhibit epithelial and neuroendocrine features. It is believed that its role is to modulate mechanic-reception [3-6,7].

Each year 1,500 new cases of MCC are diagnosed in the USA and 2,500 new cases in Europe, with rising incidence over the past few decades. It is still unclear if this trend is due to an aging population or increased awareness and diagnosis. These cancers most often appear on parts exposed to the sun, with the face and neck being the most common sites, but it can be found anywhere on the body. Carcinogenesis in MCC is the result of mutations induced by UV-radiation or by the clonal integration of the Merkel cell polyomavirus into the host genome, determining patterns of multiple DNA mutations. [8] $80 \%$ of cases are virus-positive, and $20 \%$ of MCCs are virus negative. Immune-escape is found in both types and as a result, immune checkpoint therapies involving PD-1/PD-L1 shown to determine a good response in both viral and non-viral subtypes of MCC.

Merkel cell carcinomas (MCCs) lacks distinctive clinical features. Approximately $25 \%$ of cases have involvement of regional lymph node, and less than $2 \%$ of the patients are diagnosed with the unknown primary site. AEIOU acronym, developed by Heath et al., is used to summarise clinical characteristics that define MCC, and comprise of asymptomatic or lack of tenderness, rapid expansion, immune suppression, age more than 50 years, and UVexposed site on a person with fair skin [1-4, 9].

The positive diagnosis is based on histopathology and immunohistochemistry. In 2015 a group of interdisciplinary experts from the European Dermatology Forum (EDF), the European Association of Dermato-Oncology (EADO), and the European Organization of Research and Treatment of Cancer (EORTC) established the Guidelines for diagnosis and treatment of Merkel cell carcinoma [1-4, 9-11].

The extent of the disease relates best witht prognostic factors. The best survival is seen in patients with localized disease (65-85\% 5y survival). The five years survival rate for metastatic disease is approximately $25 \%$. In recent years, there have been major advanced in our understanding of MCC biology, but survival rates remain low [1-4, 9].

Therapeutic options for MCC depends on the stage of disease at presentation, location of the tumor, regional lymph node involvement, comorbidities, and performance status of the patient. It is a multimodal treatment including surgery, chemotherapy, radiotherapy, and immunotherapeutic treatments that are showing promising early results. Inclusion in clinical trials is recommended in disseminated Merkel cell carcinoma [1-3, 9-12].

Surgical intervention like Mohs microsurgery is commonly used. Surgery resulting in positive margins should be followed by re-excision. Patients unfit for excision can be treated with radiotherapy. Radical lymphadenectomy is recommended in patients with involved regional lymph nodes. Sentinel biopsy could be recommended in case of no clinical evidence of regional lymph node involvement.

Current treatment options consist of wide local excision with adjuvant radiotherapy [1, 2, 9, 11-15].

Studies have shown that adjuvant radiotherapy reduced the probability of recurrence compared with surgeryalone. Radiotherapy is indicated as palliative treatment for inoperable cases of MCC for tumor control, pain, bleeding, ulceration, and secondary infections [1, 2, 8, 12, 16-19,20].

Until recent years chemotherapy was the only systemic option for many years for advanced-stage or metastatic 
MCC. Chemotherapy is mainly reserved for the treatment of metastatic MCC [1- 3, 9-12, 21-23].

The efficacy of immune-checkpoint inhibitors was demonstrated due to several clinical trials that revealed the high immunogenicity of MCC.

Predictive biomarkers could help guide the multimodal treatment [12, 24-27].

Avelumab (Bavencio), a programmed death 1 (PD-1) inhibitor was approved by the US Food and Drug Administration (FDA) in 2017 for metastatic Merkel cell carcinoma, based on the JAVELIN Merkel 200 clinical trial [12, 28-31]. Avelumab had accelerated approval, and it is the first drug approved for patients with MCC.

The anti-PD-1 antibody, Pembrolizumab also demonstrated clinical activity in treatment-naive patients with stage IIIB/IV MCC, and showed to be effective in both virus-positive and -negative tumors. Based on these results, pembrolizumab was approved as a treatment option for MCC [12, 32-34].

The role of the anti-PD-1 antibody, Nivolumab in MCC treatment was investigated in the CheckMate 358 clinical trial, and the conclusions were that Nivolumab induced a rapid and sustainable tumor response in the majority of patients with advanced MCC, either treatment-naive or not. As a result, in 2018, Nivolumab was included in the NCCN guidelines for MCC, as a treatment option for disseminated disease $[12,32,34]$.

\section{Experimental part}

We retrospective analyzed the incidence of Merkel cell carcinoma (MCC) in Oncology Department I at Prof. Dr. Alexandru Trestioreanu Institute of Oncology, Bucharest, Romania and reviewed 3 cases of patients diagnosed with Merkel cell carcinoma between 2000 and 2018. Patients characteristics were obtained from medical records. All patients signed informed consent before oncological treatment.

The first patient diagnosed with Merkel cell carcinoma in our clinic was a 73y old female, with no essential comorbidities. In 2002 she was referred to the dermatology department for a right prefrontal region lesion. The biopsy excision indicated Merkel cell carcinoma, and the imaging scans showed superficial infiltration without distant metastasis. Mohs tumor excision was performed with negative sentinel node biopsy. She had no recurrence during her 5-year follow-up, including a physical examination (and dermatological examination), biological tests and periodically imaging revaluation.

The second patient, a 55 years old male patient, was diagnosed in 2012 with Merkel cell carcinoma of the left arm. His past medical history included an excised parietal, frontal basal cell carcinoma in 2003. The present lesion was firm, indurated, erythematous with no associated pain, but with enlarged left axillary lymph nodes. Biopsy from the primary tumor diagnosed a Merkel cell carcinoma, that was confirmed by two separate immuno-histochemistry reports. CT scans of the chest, abdomen, and pelvis revealed the primary tumor and enlarged left axillary lymph nodes. Laboratory tests were normal, and dermatological examination for other lesions or skin malignancies were negative. The patient underwent complete wide local excision of the lesion with axillary lymphadenectomy. Pathological analysis showed a completely excised $5.5 \mathrm{~cm}$ ulcerated MCC lesion with negative margins and positive lymphovascular invasion stage pT3pN1b. Adjuvant radiotherapy treatment after surgical excision was indicated, and conventional fractionation (1 fraction/day, five days/week; total dose $=60$
Gray/30 fractions) was performed with no important adverse events during treatment. The multidisciplinary tumor board decided that no adjuvant chemotherapy was indicated since this is mainly reserved for treatment of metastatic MCC. Follow-up continued with physical and dermatological examinations, biological tests, and periodically imaging tests. After three years from diagnosis, the follow-up CT of the chest, abdomen, and pelvis displayed increasing supraclavicular and mediastinal lymph node and multiple pulmonary metastases. The patient started chemotherapy-CAV regimen (cyclophosphamide, doxorubicin, vincristine), with multiple adverse events during treatment. After four cycles, his performance status decreased, and CT scans showed progressive disease. The patient refused second-line treatment and was referred to the palliative care unit.

The third case treated in our department is of a 21 years old patient, with no other comorbidities, diagnosed in February 2018 with unknown primary Merkel cell carcinoma. The patient first addressed the primary care physician for an enlarged left inguinal adenopathy and was referred to a plastic surgery department were excisional lymph node biopsy was done. The histopathological report showed infiltrative carcinoma cells of unknown primary origin and recommended immunohistochemistry. First immunohistochemistry indicated CK20+, TTF1-, CK7-, and CDX2- neuroendocrine carcinoma with the most likely starting point being a Merkel carcinoma. Second immunohistochemistry confirmed the diagnosis of Merkel cell carcinoma.

Whole-body MRI performed in march 2018 indicated left external iliac lymph node (31/14/8 mm) with slightly thickened cortex and bilateral enlarged inguinal lymph nodes $(20 / 10 / 13 \mathrm{~mm})$, with the thickened cortex (Figure 1).

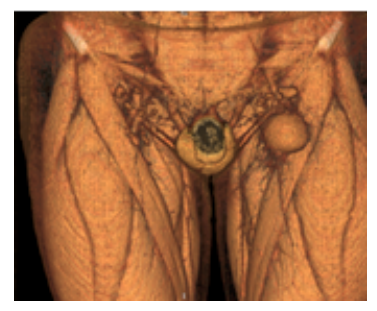

Fig.1. Whole-body MRI-enlarged lymph nodes

Physical examination (including dermatological examination) was normal, and no primary lesion was identified. Biological tests, including beta-HCG and AFP, were in normal ranges. The PET-CT revealed metabolically active lesions in the left inguinal area (Figure 2).



Fig. 2. PET-CT - metabolically active lesions left the inguinal area

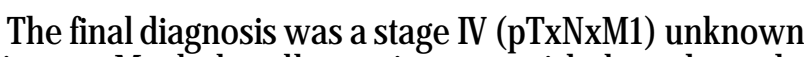
primary Merkel cell carcinoma with lymph node metastases.

The multidisciplinary tumor board decided that the first approach in the treatment plan for this patient should be postoperative local radiotherapy. VMAT radiotherapy, with conventional fractionation ( 1 fraction/day, 5 days/week; total dose $=60$ Gray/30 fractions) was performed. Target areas were adenopathies located in the inguinal and left 
external iliac, left inguinal lymph node area and postoperative seroma. (Figure 3). The patient presented minor adverse events -grade I neutropenia and grade I and II radiodermatitis, all managed according to the local guidelines.

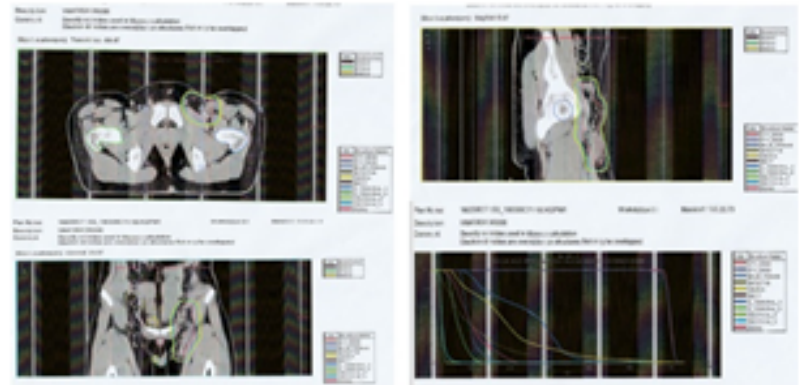

Fig. 3. Radiotherapy treatment plan

According to the national and international guidelines, the multidisciplinary tumor board recommended immunotherapy as the first-line treatment option. The patient started treatment with Avelumab.

Pretreatment screening was performed. Laboratory tests, including TSH, FT3, FT4 were normal, HBV, HCV and HIV negative, and the ECG and echocardiography within normal limits. Given the age of the patient, he was informed about the risk of infertility and the fact that there are insufficient data on infertility and was advised on preserving sperm. The patient started treatment with Avelumab, 10 $\mathrm{mg} /$ per kilogram, 60 min intravenous administration, with premedication 30-60 min prior administration (H1antihistamine and acetaminophen) as per protocol, repeated every two weeks.

Follow-up during treatment included physical and dermatological examinations, biological tests, including TSH, FT3, FT4 and imaging revaluation at six months $[35,36]$.

After four cycles of Avelumab the biological tests indicated a reduced value of TSH $(\mathrm{TSH}=0.0101 \mathrm{U} / \mathrm{mL})$ with slightly enhanced values of FT3 $=4.81 \mathrm{pg} / \mathrm{mL}$; FT4 $=1.57$ $\mathrm{ng} / \mathrm{dL}$; thyroid echography and ECG were normal. Endocrinologic examination diagnosed a grade 2 (according to Common Terminology Criteria for Adverse Events-CTCAE) iatrogenic hyperthyroidism due to immunotherapy, and the patient started Thyrozol $30 \mathrm{mg} /$ day and Atenolol 1/2 cp x 2/day (because of tachycardia). Evolution of thyroid dysfunction during treatment with Avelumab is presented in Figure 4. After iatrogenic hyperthyroidism secondary to Avelumab, the patient presented hypothyroidism. The dose of Thyrozol was reduced to $2.5 \mathrm{mg} /$ day, and the remission of hypothyroidism was achieved.

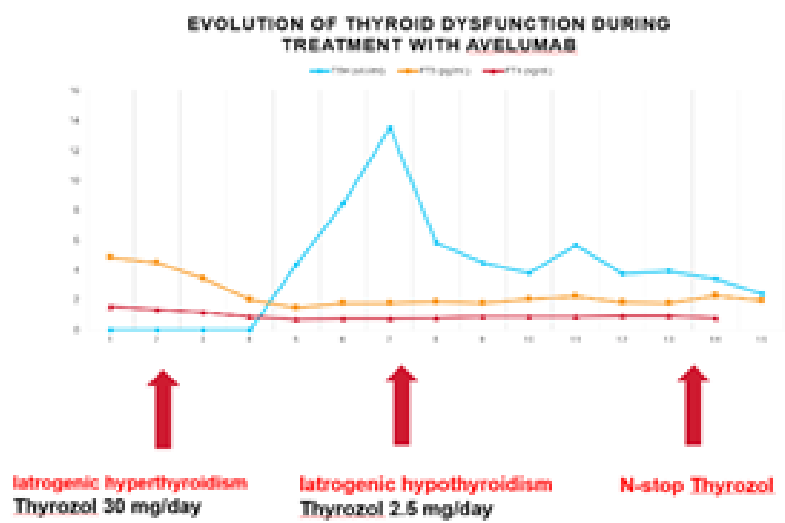

Fig. 4. Evolution of thyroid dysfunction during treatment with Avelumab
Radiology exams performed after six months (August 2018), brain and chest CT scan and abdominopelvic MRI, showed partial regression of inguinal adenopathy compared with the PET-CT examination from April 2018 and with MRI from February 2018 (Figure 5).

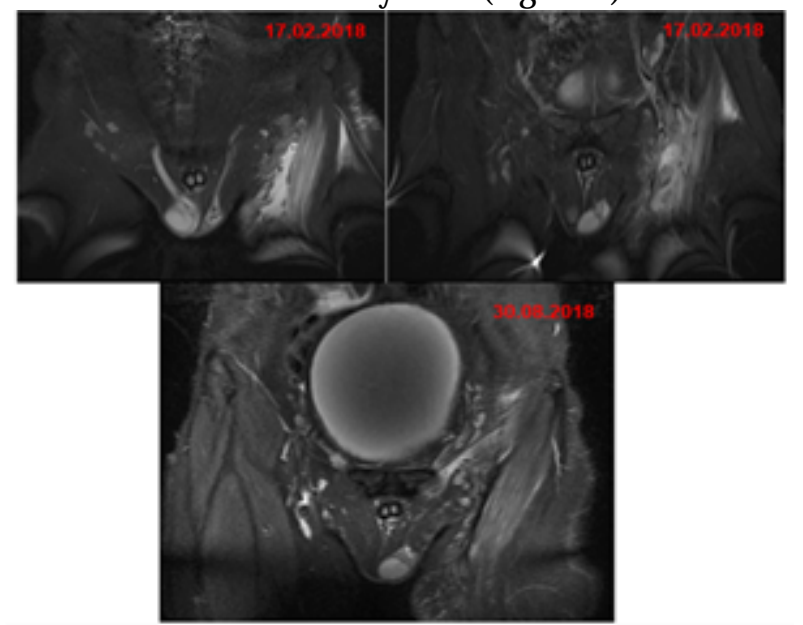

Fig. 5. MRI re-evaluation at six months

Further radiology re-evaluation in November 2018 and February 2019 during treatment with Avelumab showed no pathological abdominopelvic masses and unchanged several bilateral inguinal nodes, compared with August 2018 examinations. PET-CT examination from April 2019 (Figure 6) showed no signs of metabolically active lesions left the inguinal area, compared to the PET-CT examination from 2018.

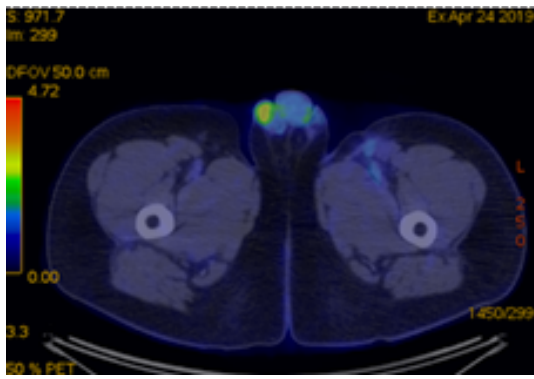

Fig. 6. PET-CT

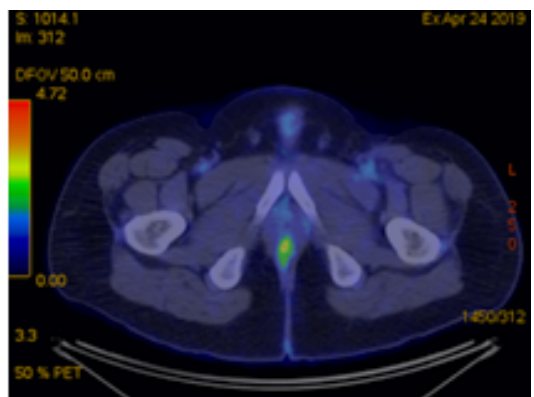

reevaluation in 2019

The patient continued the treatment with Avelumab with no adverse events during treatment.

Regarding the particularities of this third case we can emphasize on the young age of the patient at diagnosis (21 years old), the rare form of skin cancer-Merkel cell carcinoma, lymph node metastasis with no primary tumor, limited treatment options and a favorable treatment response -the patient maintained the remission similar to data from JAVELIN Merkel 200 (NCT02155647). It is also important to mention the iatrogenic hyperthyroidism due to Avelumab.

\section{Results and discussions}

Compared to other types of cancer, Merkel cell carcinoma (MCC) is a rare and aggressive anaplastic carcinoma of the skin that usually occurs in elderly people over 65 years of age [37-43]. MCC has the highest mortality 
rate among skin malignancies and a tendency to recur within the first year after surgical resection.

Our clinical experience is limited to this type of malignancy, due to the rarity of the condition; only three cases were diagnosed and treated in our department. Age differed for the three patients, and the only known risk factor that was common was UV exposure. Merkel cell polyomavirus (MCPyV) infection was not determined because it is not used in our practice.

The first patient had a follow-up at five years, with no evidence of relapse, and the youngest patient is still on monitoring with only one year of treatment. Unfortunately, one of the patients died three years after diagnostic.

The first patient had good a good prognosis: superficial infiltration without distant metastasis, negative sentinel node biopsy, and no recurrence after 5-years of follow-up. The other two patients had poor prognostic factors: positive lymphovascular invasion, positive lymph nodes, metastatic disease, casexia[44-46].

The second patient relapsed three years after diagnosis. For the youngest patient is still early to appreciate relapsefree survival.

For the second patient, chemotherapy was the only option at the time when metastatic relapse was confirmed. There was no response to treatment, and his quality of life decreased significantly, and best supportive care as indicated.

Although the patient who received Avelumab had poor prognosis factors: young age (21 years old) at diagnosis, the rare form of skin cancer (limited data in the literature on Merkel cell carcinoma), lymph node metastasis with no primary tumor, fortunately, the patient maintained the remission similar to data from JAVELIN Merkel 200 (NCT02155647) - Avelumab in first line.

The data from the literature suggests there are limited treatment options and we can appreciate that in this case immunotherapy was the best option for the young patient (as current guidelines recommend) since there are no randomized studies comparing different chemotherapy regimens or chemotherapy versus immunotherapy, and most recommendations are based on aggregate case studies. During treatment with Avelumab, the patient maintained a good quality of life and presented iatrogenic hyperthyroidism, but reversible with treatment as per immune-related adverse events guidelines.

\section{Conclusions}

There are no predictive biomarkers regarding a response that could help to better select patients, and additional research is essential, especially with the development of immunotherapy agents that have the potential to provide effective treatment options for patients with advanced or recurrent MCC. Furthers studies are needed to develop treatment protocols for advanced and metastatic disease.

\section{References}

1.MAZILU, L., CIUFU, N., GALAN, M., SUCEVEANU, A.I., SUCEVEANU, A.P., PAREPA, I.R., TOFOLEAN, D.E., Chirurgia, 107,nr.1,2012, p 55-58, 2.SUCEVEANU, A.I., SUCEVEANU, A.P., VOINEA, F., MAZILU, L., MIXICI, F., ADAM, T., An International Journal of Gastroenterology and Hepatology,18,nr.1, 2009,p 33-38.

3.CHMIELOWSKI, B., TERRITO, M., Manual of Clinical Oncology $8^{\text {th }}$ Edition, Lippincott Manual, Wolters Kluwer, 2017.

4.BECKER J.C, STANG,A., HAUSEN ZUR,A., FISCHER,N et al.,Cancer Immunol Immunother. 67,nr.3,2018,p.341-351.

5.SUNSHINE, J. C., J AHCHAN, N. S., SAGE, ., CHOI,J ., Oncogene, 37,2018,p.409-1416.

6.SCHADENDORF, D., LEBBÉ, C., HAUSEN ZUR A., ET AL., Eur J Cancer.,71,2017,p.53-69.
7.BOLOCAN, A.,PADURARU, D.N.,NITIPIR, et al.,ROMANIAN BIOTECHNOLOGICAL LETTERS,23,nr.6,2018,p.14193-14202

8.XIE, H., LEE, L., CARAMUTA, S., HOOG, A., BROWALDH, N., B] ÖRNHAGEN, V., et al., J Invest Dermatol.,134,nr.2,2014,p.507-517. 9.LEBBE, C., BECKER, J.C., GROB, J.J., et al.,Eur J Cancer.,51,nr.16,2015,p.2396-403.

10.VICTOR,A.I., SAHASRABUDHE,D.M, Clinical Skin Cancer,1,nr.2, 2016,p.66-74.

11.AMARAL,T., LEITER,U., GARBE,K., Reviews in Endocrine and Metabolic Disorders,18,nr.4,2017,p. 517-532.

12.*** National Comprehensive Cancer Network. NCCN Clinical Practice Guidelines in Oncology: Merkel Cell Carcinoma, 2016.

13.WASSERBERG, N., SCHACHTER, J., FENIG, E., et al. Dermatol Surg., 26,nr.2,2000,p.138-41.

14.ZEITOUNI, N.C., CHENEY, R.T., DELACURE, M.D.. Dermatol Surg.,26,nr.1,2000,p. 12-8.

15.PULITZER, M., Surgical Pathology Clinics, 10,nr.2,2017,p. 399-408. 16.KIM, J.A., CHOI, A.H., JAMA Dermatol., 149,nr.7,2013,p. 831-8.

17.BHATIA, S., STORER, B.E., IYER, J.G., MOSHIRI, A., PARVATHANENI, U., BYRD, D., et al., J Natl Cancer Inst.,108,nr.9,2016,p.1-9.

18.BISHOP, A.J ., GARDEN, A.S., GUNN, G.B., et al., Head Neck., 38(Suppl 1), 2015, E452-8.

19.CHEN, M.M., ROMAN, S.A., SOSA, J.A., JUDSON, B.L., J AMA Otolaryngol Head Neck Surg., 141,nr.2,2015,p.137-41.

20.PIETROSANU, C.,ZAINEA, V., IONITA, I.G., et al. Conference: National Conference on Otorhinolaryngology and Cervical and Facial Surgery / National ENT, Head and Neck Surgery Conference Location: Arad, ROMANIA Date: JUN 06-09, 018,Sponsor(s): Univ Vest Vabile Goldis,PROCEEDINGS OF NATIONAL ENT, HEAD AND NECK SURGERY CONFERENCE,2018,p.416-421.

21.CASSLER, N.M., MERRILL, D., BICHAKJIAN, C.K., BROWNELL, I., Curr Treat Options Oncol. 17,nr.7,2016,p.36.

22.DESCH, L.,KUNSTFELD, R., J Skin Cancer,ID 327150,2013,p.1-9.

23.IYER, J.G., BLOM, A., DOUMANI, R., LEWIS, C., TARABADKAR, E.S., ANDERSON, A., et al., Cancer Med.,5,2016,p.2294-2301.

24.PAULSON, K.G., IYER, J.G., TEGEDER, A.R., THIBODEAU, R., SCHELTER, J., KOBA, S., et al., J Clin Oncol.,29,2011,p. 1539-46.

25.PAULSON, K.G., IYER, J.G., SIMONSON, W.T., BLOM, A., THIBODEAU, R.M., SCHMIDT, M., et al., Am J Clin Pathol.,142,2014,p. 452-8.

26.LIPSON, E.J ., VINCENT, J.G., LOYO, M., KAGOHARA, L.T., LUBER, B.S., WANG, H., et al., Cancer Immunol Res.,1,2013,p. 54-63.

27.HIROSHI, U., Front. Oncol., 8,2018,p.1-5.

28.KAUFMAN, H.L., RUSSELL, J., HAMID, O., et al. Lancet Oncol.,17,nr.10,2016,p.1374-1385.

29.STENGER,M.., The ASCO Post, 4/5/2018.

30.HOWARD, L., KAUFMAN, J.S., RUSSELL, O.H. et.al., Cancer Research,77(13 Supplement),2017, CT079-CT079.

31.BHARMAL,M., WILLIAMS,P., HENNESSY,M., SCHLICHTING,M., HUNGER,M., MARREL,A., KAUFMAN,H., Annals of Oncology, 28 (suppl.11),2017, xi6-xi29.

32.WINKLER, J., BENDER, C., KRATOCHWIL, C., ENK, A,HASSEL, J., $\mathrm{Br}$ J Dermatol.,176,2017,p. 216- 219.

33.NGHIEM, P.T., BHATIA, S., LIPSON, E.J., KUDCHADKAR, R.R., MILLER, N.J ., ANNAMALAl, L., et al.,N Engl J Med., 374,2016,p. 254252.

34.GIRALDO,N.A., KAUNITZ,G.J ., COTTRELL,T.R., et. al., Cancer Res.,77(13 Suppl.),2017, Abstract nr 662.

35.NITIPIR, C., ALECU, L.,,SLAVU, I.,etal.,J ournal Of Mind And Medical Sciences,5,nr.12018,p. 123-128.

36.TULIN, A.,ALECU, L.,POIANA, C.,et al.,J OURNAL OF MIND AND MEDICAL SCIENCES,5,nr.2,2018,p. 278-283.

37.TOPALIAN,S.L., BHATIA,S., HOLLEBECQUE,A., et. al., Cancer Res.,77(13 Suppl.), 2017,Abstract nr CT074.

38.SUCEVEANU, A.I., PANTEA STOIAN, A.,MAZILU, L., VOINEA, F., HAINAROSIE, R., DIACONU, C.C., PITURU, S., NITIPIR, C., BADIU, D.C., CEAUSU, I., SUCEVEANU, A.P., Farmacia, 66,nr.5,2018,p.904-908,. 39.MAZILU, L., SUCEVEANU, A.I., TOMESCU, D., CIUFU, N., BAZ, R., SUCEVEANU, A.P., PAREPA, I.R., TOFOLEAN, D.E., VOINEA F., 108,nr.4,2013,p. 478-481.

REV.CHIM.(Bucharest) $\bullet 70 \diamond$ No. $9 \diamond 2019$ 
40.TUDORACHE, E., FILDAN, A.P., FRANDES, M., DANTES, E., TOFOLEAN, D.E, Clin Interv Aging.,12, 2017,p.1281-1287.

41.SUCEVEANU,A.I., MAZILU,L., NITIPIR,C., PANTEA STOIAN,A., PAREPA, I., VOINEA,C., SUCEVEANU,A.P., Rev.Chim. (Bucharest), 70, no. 5, 2019, p.1808-1811.

42.DEACU, M., TOFOLEAN, D.E., BOSOTEANU, M., ASCHIE, M., BULBUC, I., Rom J Morphol Embryol.,53,nr.1,2012,p.173-7.

43.NITIPIR, C., ORLOV, C.,POPA, A.M., et al., JOURNAL OF MIND AND MEDICAL SCIENCES,5,nr.2,2018,p. 255-260

44.CIUHU,A.N.,PANTEA-STOIAN, A.M., NITIPIR, C.,et al., Conference: $3^{\text {rd }}$ International Conference on Interdisciplinary Management of Diabetes Mellitus and its Complications (INTERDIAB) Location: Bucharest, ROMANIA Date: MAR 02-04, 2017 Sponsor(s): Assoc Renal Metab \& Nutrit Studies; AstraZeneca Diabetes; MSD Diabetes; novo nordisk; SANOFI INTERDIAB 2017: DIABETES MELLITUS IN INTERNAL MEDICINE Book Series: International Conference on Interdisciplinary Management of Diabetes Mellitus and its Complications,2017,p.139-147.
45.CIOCIRLAN, M.,DRAGHIA, L.,MANUC, D.,et al.,Conference: 3rd International Conference on Interdisciplinary Management of Diabetes Mellitus and its Complications (INTERDIAB) Location: Bucharest, ROMANIA Date: MAR 02-04, 2017 Sponsor(s): Assoc Renal Metab \& Nutrit Studies; AstraZeneca Diabetes; MSD Diabetes; novo nordisk; SANOFI INTERDIAB 2017: DIABETES MELLITUS IN INTERNAL MEDICINE Book Series: International Conference on Interdisciplinary Management of Diabetes Mellitus and its Complications,2017,p.132-138.

46.NITIPIR, C.,DIACONU, C.C.,ORLOV, C., et al.,Conference: 35th Balkan Medical Week on Healthy Ageing - An Endless Challenge Location: Athens, GREECE Date: SEP 25-27, 2018 PROCEEDINGS OF THE 35TH BALKAN MEDICAL WEEK,2018,p.133137.

Manuscript received: 7.06 .2019 